\title{
Underwater radiated noise from commercial ships in the Yellow Sea of China
}

\author{
Pengfei Jiang*, Jianheng Lin, Junping Sun, and Xuejuan Yi \\ Qingdao Laboratory, Institute of Acoustics, Chinese Academy of Sciences, China
}

\begin{abstract}
During the past decades, ship-building and engine-manufacturing have developed very quickly. The source levels of modern ships may have changed. The underwater radiated noise from many commercial ships of opportunity was measured by bottom-mounted self-contained hydrophone near the shipping lanes in the yellow sea of China one day in each month from June. 2014 to Mar. 2016. Twenty seven ships among them are selected whose peak value of $20-1000 \mathrm{~Hz}$ passing curve is $10 \mathrm{~dB}$ higher than background noise level. A Gaussian source distribution in depth direction is supposed and source levels normalized at different ranges are averaged in source levels acquisition to reduce the error of transmission loss calculation. A key result was the estimated results of RANDI-3 are much greater than measured results universally for ships whose length are larger than 200 meters, however, the two are close for ships whose length are less than 150 meters. Furthermore, the samples were divided into two categories to analyze. The broad-band source levels of modern commercial ships are not highly correlated to ship length but closely related to ship speed. The decay slope is less than RANDI-3.
\end{abstract}

\section{Introduction}

At this stage, the detecting frequency band of sonar has gradually extended to low frequency or very low frequency. The low-frequency ocean background field has been one of the research hotspots in recent years.

Among the different sources of ambient noise, merchant shipping is the principal contributor over the frequency band of $5 \mathrm{~Hz}$ to as high as $1 \mathrm{kHz}$ [1]. Maritime transport has developed rapidly in the past century, Ross [2] analyzed the noise levels measured in the mid-20th century, and suggested that the lowfrequency noise was increasing at an average rate of about $0.5 \mathrm{~dB}$ per year. In recent years, the growth rate has decreased and obtained to be $0.2 \mathrm{~dB} / \mathrm{yr}$ by Chapman [3].

Modelling is another thinking, shipping noise source model contains the distribution and source level of ships. Data analysis reveals that the shipping densities accord with Poisson random distribution at the channel area.

Qualitatively, the spectrum of the sound generated by a ship consists of a broadband component, generated by propeller cavitation, and a number of narrow-band lines generated by both propeller cavitation (the blade lines) and internal Machinery (engine, generators, pumps, etc.).

However, narrow-band lines are hard to predict. So people focus on broadband continuous spectrum prediction. The noise data from individual ships are measured and sound transmission loss (TL) was calculated to estimate ship source levels, given the known waveguide environment of the ship to the receiver, and then the relationship between ship source level and different parameters. The mean source spectra curve of selected ships is fitted, and the source spectra model for merchant ship-radiated noise is obtained.

By so far, many empirical models have been proposed, The two earliest models were proposed by Ross [4] and Urick [5], who give the broad-band source level function of merchant ships or naval vessels expressed as a function of ship length, draft and speed. On this basis, The RANDI-2 model [6] and RANDI-3 model [7] are developed based on a reference ship SSL. Thus, the individual source level can be calculated as a function of its speed and length. However, these measurements were from older ships and narrower frequency bands. Beside, different ship-types were combined into the same analysis, making it difficult to examine dissimilarities in source levels [8]. Megan and Ross [9], measured underwater radiated noise for seven types of modern commercial ships and pointed out simple models to predict source levels of modern merchant ships as a group from particular ship characteristics (e.g., length, gross tonnage, and speed) were not possible given individual ship-type differences.

Different from the above models, both the Wittekind's model and the AQUO project's model [10] considered the radiated noise was decomposed into three components. In the AQUO project's model, the parameters can be obtained by the numerical process of minimizing target function, which requires at least two different speeds and is difficult to forecast the source level of non-cooperative ships.

The history of commercial shipping is defined not only by increases in the number of ships to support

\footnotetext{
* Corresponding author: jiangpengfei@mail.ioa.ac.cn
} 
burgeoning global trade, but also increases in ship size, propulsion power, and sophistication. The designs of modern commercial ships have changed. The old model may be not suitable and need to be updated.

In this study, we took an opportunistic approach to measure radiated noise from modern commercial ships travelling to and from Qingdao Port near Dagong island in China yellow sea (Fig.1). Through screening, 27 samples were brought into analysis.

We have assumed that the source consists of a vertical distribution of incoherent point sources. The sound TL was calculated by wave number integral method (Scooter). Source levels and spectral characteristics are presented. The ships were divided into two categories. The relation between $20-1000 \mathrm{~Hz}$ broadband sound level and speed and length was analyzed.

\subsection{Data acquisition}

The measurements were undertaken by Qingdao Branch of Institute of Acoustics of Chinese Academy of Sciences over a 2-year period, 2015-2016. We measured the ambient noise and the radiated noise of merchant ships with an opportunistic bottom-mounted acoustic observatory, collecting data continuously at least one day in each month. The placement locations of acoustic observatory are near the circle points marked in Fig.1. The red point is in the sea area of Dagong island. The blue one is in the sea area of Lingshan island.

The data of ship noise were almost received in the sea area of Dagong island. The hydrophone was almost deployed near the shipping lane. As illustrated in Fig.1, the shipping lane (green line) is the key leading to Qingdao Port.

Commercial vessel activity was monitored using AIS which is installed in the rented fishing boat. During the experiment, the sound speed profiles were measured by CTD several times.

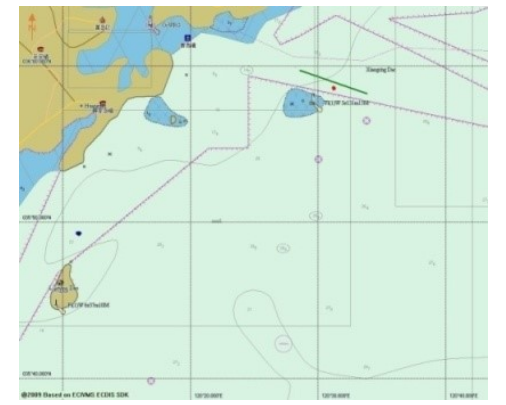

Fig. 1. Chart of experiment site.

\subsection{The closest point of approach}

The closest point of approach (CPA) was derived from ship passage information (i.e., AIS data). Generally speaking, the time when the ship reaches its CPA is determined based on the passing curves which are shown in Fig.2. For some ships, their passing characteristics are not obvious, so they need to be judged by the inflection of their "U" shaped spectrogram.
One pattern seen in the passing curves of Fig. 2 is the asymmetry between the bow and stern aspects, with more radiated energy at the stern aspects (i.e., positive time from CPA).
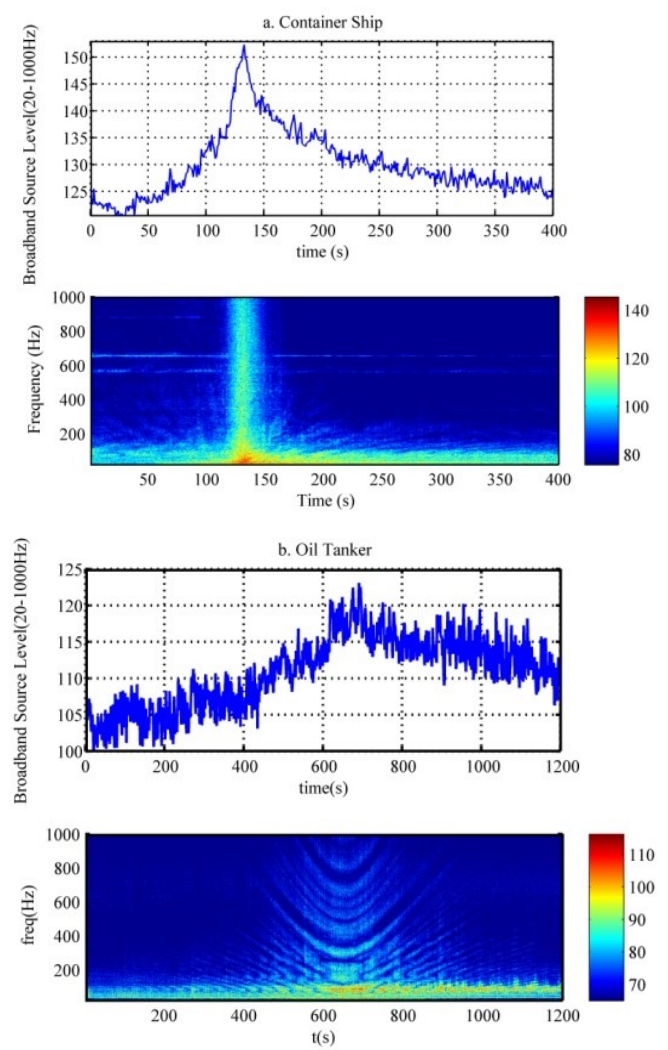

Fig. 2. Passing curve and spectrogram of ships.

(MMSI a: 477271400 b: 412667000$)$

\subsection{Background noise}

As recommended in ISO and ANSI standards, the effect of background will be ignored if the difference between the radiated noise and the background noise level is greater than $10 \mathrm{~dB}$. In data processing, by analyzing the recorded data and combining with recorded AIS, we first picked out the noise data segments with only one ship in half an hour. Second it was ensured that the Peak values are $10 \mathrm{~dB}$ more than of stationary values of passing curves before and after the time corresponding to CPA.

\subsection{Transmission loss}

It is well known that the source depth has a great influence on the TL. The previous model usually assumes that the ship's noise source is a point source at a certain depth and the error of source depth estimation is unavoidable because of the uncertainty of the carrier's load. In order to reduce the normalization error, the propagation function for each ship was computed by representing the source region as a vertical line distribution of incoherent point sources. A wave number integration model (scooter) was used to compute the propagation function from each of the point sources. The sound speed profiles were obtained by meaning measured results during the experiment. Based on the chart and the nearby sound propagation experiment, it is 
assumed that the bottom of the sea is mud bottom and not clearly stratified.

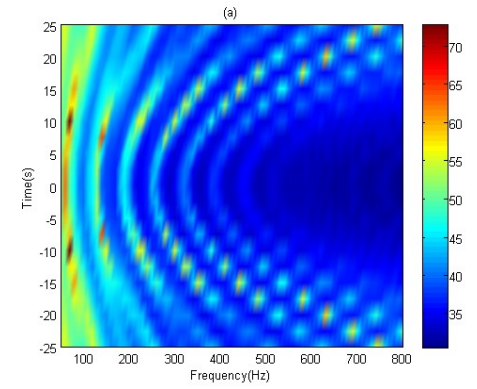

(a) Point source

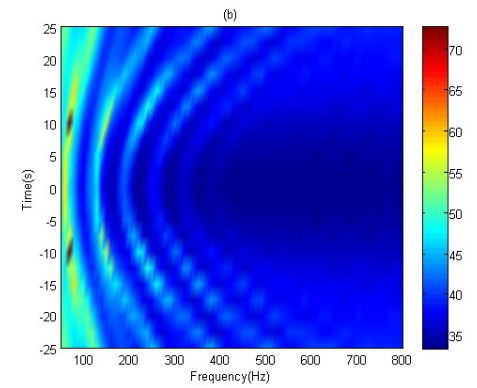

(b) Using a Gaussian source distribution

Fig. 3. TL under different assumptions.

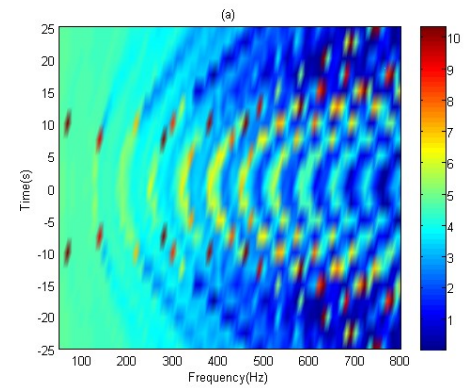

(a) Point source

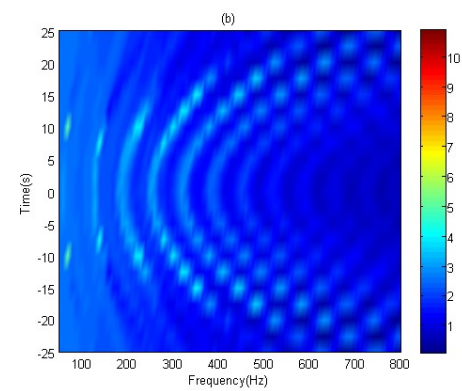

(b) Using a Gaussian source distribution

Fig. 4. Error of TL caused by mistake of source depth under different assumptions.

The point sources were weighted according to a Gaussian along the propeller disk with a standard deviation equal to one quarter of the propeller diameter. These are a consequence of the individual propeller blade passing through the uneven wake field behind the ship. The areas with the highest wake (smallest axial flow velocity into the propeller) in a single-screw ship are observed in the upper region (around the 12 o'clock position) of the propeller disk. Under these conditions, we assumed cavitation bubbles form mostly in the upper quarter quadrant of propeller disk and the weighting of source intensity with depth satisfies a Gaussian distribution.

$$
\overline{T L}=-10 \times \log 10\left(\frac{\sum_{z} W(z) 10^{-\frac{T L(z)}{10}}}{\sum_{z} W(z)}\right)
$$

Fig. 3 shows the variation of TL with time and frequency in two cases of source depth Gauss distribution and point source. Fig. 4 is that the error of TL caused by the mistake of source depth, the ship speed is 18 , the draft of the full load is 10 meters, and the actual draft is 9 meters. It can be seen that when the Gauss distribution is assumed, the fluctuation of TL with frequency is obviously smaller than that of the point source; when the ship is not fully loaded and the source depth is not accurate, the error of the former is much smaller than that of the former.

\section{Analysis}

Table 1 provides a selected ship samples, 9 cargo ships, 13 container ships and 5 tankers, of which the length of the container ship is all more than 200 meters, and the bulk carrier and the oil tanker are mostly less than 150 meters. Fig.5 shows the variation of $20-1000 \mathrm{~Hz}$ broadband source level of ship with the length. For all samples, there is no obvious correlation between the two. The blue circle is the broadband noise source level of the ship, and the red box is calculated value of RANDI-3. For the ships whose length is more than 200 meters, the calculation results of RANDI-3 model are generally higher than the measured results and the maximum gap can reach $15 \mathrm{~dB}$. The main reason may be the TL was calculated by propagation program which is affected by source depth, while the source depth is closely related with ship length, the longer the ship, the deeper the source depth. The TL is smaller than which is estimated by spherical spreading in the former model. Another reason is the former models involved few such large ships. For the ships whose length is less than 150 meters, there is little gap between the RANDI-3 calculation results and the measured ones.

Based on the above analysis, the sample of Table 1 is divided into two categories to set up the ship noise source level model respectively. Category I whose length is 200 meters above contains 13 containers, 1 cargo ships. Category II whose length is 150 meters below contains 7 cargo ships and 4 tankers.

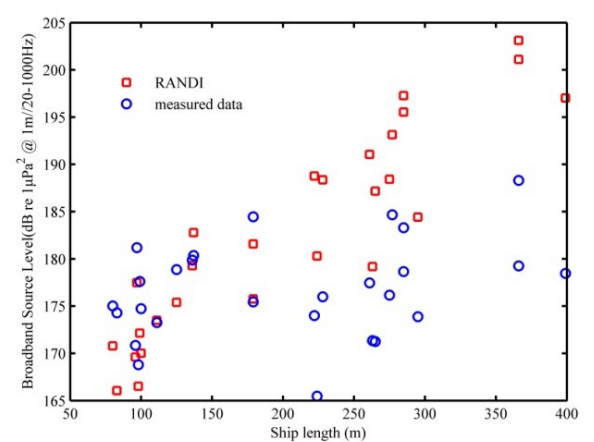

Fig. 5. Broad-band source level changes with ship length. 
Fig.7 shows the variation of the broad-band source level of ships whose length is greater than 200 meters and less than 150 meters with speed. It can be seen that the two have a good correlation. For the ships whose length is greater than 200 meters, the correlation coefficient is 0.8513 , and the function of linear fitting is

$$
S S L_{20-1000 \mathrm{~Hz}}=116.85+51.7 \times \lg (v)
$$

For the ships whose length is less than 150 meters, the correlation coefficient is 0.8533 , and the function of linear fitting is

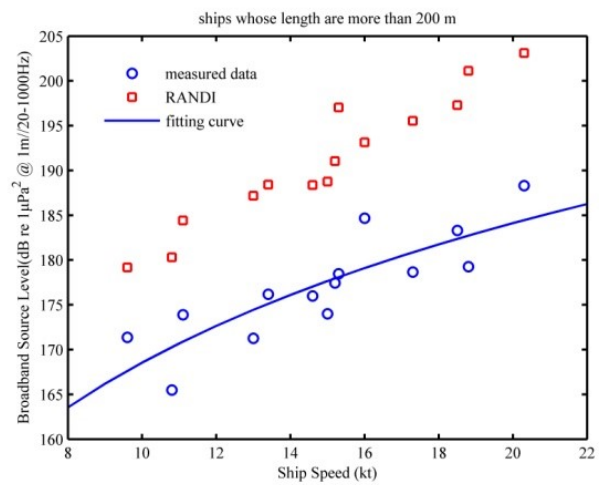

Fig. 6. Broad-band source level changes with ship velocity.

$$
S S L_{20-1000 \mathrm{~Hz}}=121+52.37 \times \lg (v)
$$

Considering that the model is mainly aimed at the continuous spectrum of ship noise, this paper first smoothed the source level spectra of the measured ships. Fig. 7 and 8 respectively give the smoothed results and the position distribution of the hump for two categories of ship. It can be seen that the humps of source level spectra are mostly located in the $30-50 \mathrm{~Hz}$. The distribution of the humps for category I is relatively concentrated, which is favorable for modelling the source level.

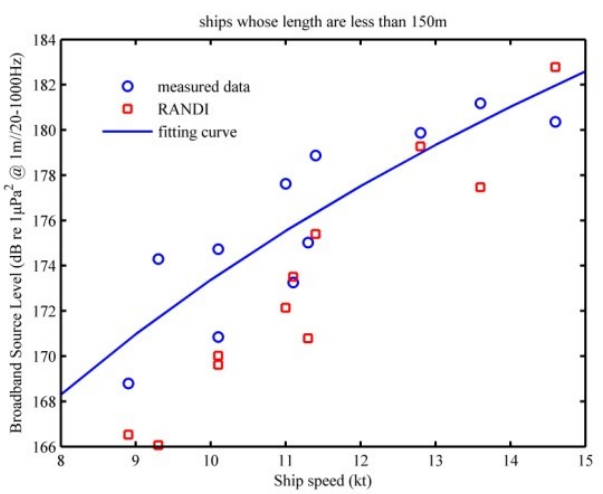

\begin{tabular}{|c|c|c|c|c|c|c|c|}
\hline MMSI & $\begin{array}{l}\text { Length } \\
\text { (m) }\end{array}$ & $\begin{array}{c}\text { Velocity } \\
\text { (kt) }\end{array}$ & $\begin{array}{c}\text { Draft } \\
\text { (m) }\end{array}$ & $\begin{array}{c}\text { Distance at } \\
\text { CPA (m) }\end{array}$ & $\begin{array}{l}\text { Received level } \\
\text { at CPA (dB) }\end{array}$ & $\begin{array}{l}\text { Broad band source } \\
\text { level }(20-1000 \mathrm{~Hz})\end{array}$ & Ship type \\
\hline 564341000 & 137 & 14.6 & 6.2 & 354.6 & 124.4589 & 180.3622 & Cargo \\
\hline 413323640 & 96 & 10.1 & 5.4 & 299.3 & 119.5769 & 170.8488 & Cargo \\
\hline 412452390 & 98 & 8.9 & 5.9 & 1045.6 & 109.5957 & 168.7955 & Cargo \\
\hline 441950000 & 80 & 11.3 & 5.2 & 623.3 & 116.9455 & 175.0230 & Cargo \\
\hline 305871000 & 179 & 12.5 & 8.4 & 591.5 & 121.0316 & 175.4445 & Cargo \\
\hline 636091345 & 224 & 10.8 & 14 & 594.7 & 115.4875 & 165.4806 & Cargo \\
\hline 413370770 & 83 & 9.3 & 5.4 & 582.9 & 118.1522 & 174.2933 & Cargo \\
\hline 440098000 & 99 & 11 & 5.5 & 527.2 & 121.9415 & 177.6180 & Cargo \\
\hline 412330570 & 111 & 11.1 & 4.6 & 115.6 & 127.7792 & 173.2576 & Cargo \\
\hline 357737000 & 285 & 17.3 & 12.7 & 1382 & 119.0897 & 178.6661 & Container \\
\hline 565357000 & 228 & 14.6 & 9.5 & 1345.9 & 115.0434 & 175.9937 & Container \\
\hline 368685000 & 277 & 16 & 10 & 1322.6 & 125.2561 & 184.6638 & Container \\
\hline 41314900 & 263 & 9.6 & 12.8 & 1219 & 114.2085 & 171.3599 & Container \\
\hline 210268000 & 222 & 15 & 7.9 & 648.9 & 117.5775 & 173.9946 & Container \\
\hline 218070000 & 295 & 11.1 & 10 & 517.4 & 119.4515 & 173.8814 & Container \\
\hline 566372000 & 275 & 13.4 & 9.9 & 730.8 & 122.2099 & 176.1734 & Container \\
\hline 477319300 & 261 & 15.6 & 11.7 & 515.4 & 125.9051 & 177.4516 & Container \\
\hline 215237000 & 366 & 18.8 & 8.5 & 1034.5 & 121.5660 & 179.2499 & Container \\
\hline 219632000 & 399 & 15.3 & 11.4 & 497.5 & 127.5151 & 178.4701 & Container \\
\hline 255805568 & 265 & 13 & 9.9 & 352.1 & 119.2105 & 171.2502 & Container \\
\hline 357939000 & 285 & 18.5 & 11.1 & 432.2 & 129.1728 & 183.2969 & Container \\
\hline 477271400 & 366 & 20.3 & 12.9 & 53 & 145.8427 & 188.3017 & Container \\
\hline 355057000 & 97 & 13.6 & 4.6 & 823.2 & 117.7931 & 181.1826 & Tanker \\
\hline 412667000 & 136 & 12.8 & 6 & 629.3 & 120.7400 & 179.8700 & Tanker \\
\hline 413434360 & 100 & 10.1 & 3.6 & 534.3 & 115.1486 & 174.7270 & Tanker \\
\hline 412764650 & 125 & 11.4 & 5.5 & 474 & 122.3878 & 178.8736 & Tanker \\
\hline
\end{tabular}

Table 1. Information of selected ships. 


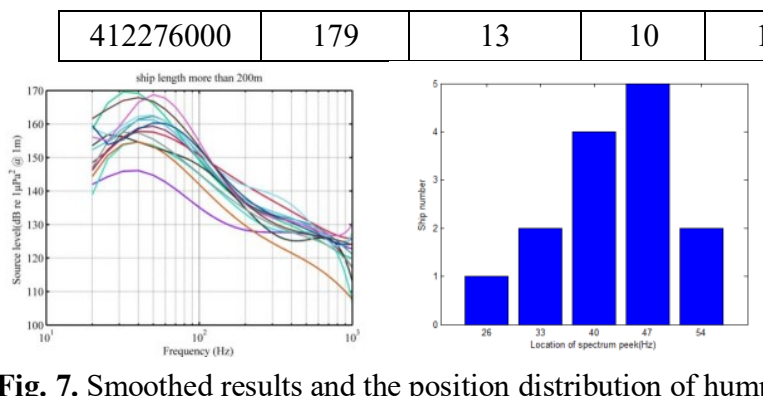

Fig. 7. Smoothed results and the position distribution of humps for category I.
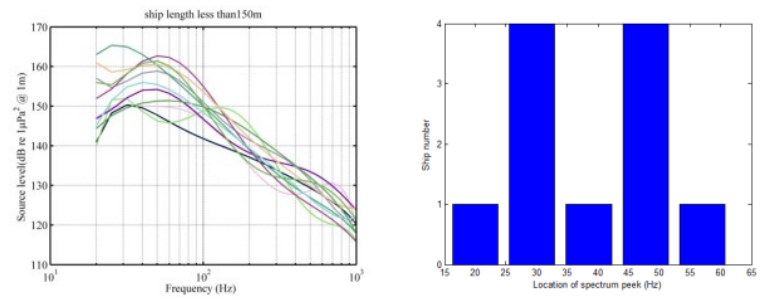

Fig. 8. Smoothed results and the position distribution of humps for category II.

\section{Summary}

We measured the ambient noise and ship noise in the Yellow Sea using a bottom-mounted and self-contained hydrophone. 27 ship samples were selected and analyzed with signal-to-noise ratio greater than $10 \mathrm{~dB}$ in this paper.

For deriving the estimates of the source spectra from that data, we assumed that the source consists of a vertical distribution of incoherent point sources. The point sources were weighted according to a Gaussian with a standard deviation equal to one quarter of the propeller diameter. This assumption can effectively reduce the error caused by misestimation of the source depth, and is more consistent with the actual distribution characteristics of cavitation bubbles.

Beside, this paper analyzed the correlation between the ship's broadband source level and the length and speed of the ship. For all the samples, there is no obvious correlation between the ship's broadband source level \begin{tabular}{|c|c|c|}
\hline 126.3372 & 184.4545 & Tanker \\
\hline
\end{tabular} categories (the length is more than 200 meters and less than 150 meters). The results show that the ship's broadband noise source level is closely related to the speed of the ship, and the correlation coefficient is above 0.85 . In addition, the humps of source level spectra are mostly located in the $30-50 \mathrm{~Hz}$. The distribution of the humps for category I is more concentrated.

This work was supported by the Fund of Acoustics Science and Technology Laboratory.

\section{References}

1. Wenz G. M, J. Acoust. Soc. Am., 34, 1936 (1962)

2. Ross, D, IEEE J. Ocean. Eng. 30, 257 (2005)

3. Chapman. N, R. Price, J. Acoust. Soc. Am. 129, 161 (2011)

4. Ross. D, Mechanics of Underwater Noise (New York: Pergamon, 1976)

5. URICK. R, Principles of Underwater Sound ( New York, McGraw-Hill, 1983)

6. Hamsom. R. H, Wagstaff, R. A, Report SR-70, SACLANT ASW, LaSpezia, Italy, (1983).

7. J. E. Breeding, Jr., L. A. Pflug, M. Bradley, M. H. Walrod, and W. McBride, NRL Report, NRL/FR/7176-95-9628, Naval Research Laboratory, Stennis Space Center, (1996)

8. Stephen C. Wales and Richard M. Heitmeyer, J. Acoust. Soc. Am. 111, 1211 (2002)

9. Megan F. McKenna, Donald Ross, J. Acoust. Soc. Am. 131, 92 (2012)

10. Audoly, C, Gaggero, T, Baudin, E, et al. IEEE J. Ocean. Eng. 42, 373 (2017) 